\title{
POLÍTICAS \\ LINGUÍSTICAS \\ AUTÓCTONES \\ E LÍNGUAS \\ INDÍGENAS \\ EM RORAIMA: \\ O CASO \\ DO POVO \\ YE'KWANA
}

\section{POLÍTICAS LINGÜÍSTICAS AUCTÓCTONAS Y LENGUAS INDÍGENAS EN RORAIMA: EL CASO DEL PUEBLO YE'KWANA}

AUTOCHTHONOUS LINGUISTIC POLICIES AND INDIGENOUS LANGUAGES IN RORAIMA: THE CASE OF THE YE'KWANA PEOPLE

Marcus Vinícius da Silva*

Colégio de Aplicação da Universidade Federal de Roraima

Isabella Coutinho Costa**

Universidade Estadual de Roraima

Cristiani Dália de Mello***

Universidade Estadual de Roraima

\footnotetext{
* Doutorando em Linguística pelo Programa de Pós-Graduação em Linguística e Língua Portuguesa da Universidade Estadual Paulista Júlio de Mesquita Filho (UNESp-Araraqua); Professor do Colégio de Aplicaça da Universidade Federalde Roraima (CAp/UFRR). E-mail: marcus.silva@ufrr.br.

** Doutora em Linguística pelo Programa de Pós-Graduação em Linguística Universidade Federal do Rio de Janeiro (UFR); Professora do Curso de Letras da Universidade Estadual de Roraima (UERR). E-mail: isabella_coutinho@hotmail.com.

*** Doutora em Linguística e Língua Portuguesa pelo Programa de Pós-Graduação em Linguística e Língua Portuguesa da Universidade Estadual Paulista Júlio de Mesquita Filho (UNESp-Araraquara); Professora do Curso de Letras da Universidade Estadual de Roraima (UERR). E-mail: crisdaliamello@hotmail.com.
} 
RESUMO: O artigo proposto tem como objetivo refletir sobre as políticas linguísticas autóctones desenvolvidas por e para os povos indígenas do estado de Roraima, dada a realidade multilíngue e multicultural da constituição do estado, com especial atenção para as ações educacionais desenvolvidas pelo povo Ye’kwana. Para isso, a baseamo-nos nos estudos da área de Políticas Linguísticas (CALVET; 2007; COOPER; 1997[1989]; SILVA, 2018), a fim de compreender as relações tensivas entre o estado brasileiro e as línguas indígenas de Roraima. Para tanto, foi necessário recuperar pesquisas realizadas sobre os Ye’kwana (COSTA, 2013, 2018, 2019); (ANDRADE, 2007, 2013), bem como foi importante resgatar, de forma breve, a história das políticas linguísticas para os povos indígenas no Brasil para, assim, discutir sobre as políticas linguísticas autóctones pensadas e desenvolvidas por/para os povos indígenas no território roraimense (CUNHA, 2008; BRASIL, 1988, 1998; BANIWA, 2006; REPETTO, 2008). Percebemos que, em função da omissão do Estado, os Ye’kwana e outros povos indígenas têm buscado criar políticas para manter seus valores tradicionais dentro das necessidades que a contemporaneidade e a sociedade exigem, ao documentar e criar estratégias para ensinar e aprender suas próprias línguas e culturas, sem perder a sua essência e sua identidade.

PALAVRAS-CHAVE: Políticas Linguísticas. Línguas Indígenas. Ye’kwana. Roraima.

RESUMEN: El artículo propuesto tiene como objetivo reflejar sobre las políticas lingüísticas autóctonas desarrolladas por y para los pueblos indígenas del estado de Roraima, dada la realidad multilingüe y multicultural de constitución del estado. Para ello, nos basamos en los estudios del área de Políticas Lingüísticas (CALVET, 2007); (COOPER, 1997[1989]; SILVA, 2018), con la finalidad de comprender las tensas relaciones entre el estado brasileño y las lenguas indígenas de Roraima. Para tanto, fue necesario recuperar las investigaciones realizadas sobre los Ye'kwana (COSTA, 2013, 2018, 2019; ANDRADE, 2007, 2013), además fue importante rescatar, de forma breve, la historia de las políticas lingüísticas autóctonas pensadas y desarrolladas por y para los pueblos indígenas en territorio roraimense (CUNHA, 2008; BRASIL, 1988, 1996; BANIWA, 2006; REPETTO, 2008). Percibimos que, en función de la omisión del Estado, los Ye'kwanas y otros pueblos indígenas tienen buscado crear políticas para mantener sus valores tradicionales dentro de las necesidades que la contemporaneidad y la sociedad exigen, al documentar y criar estrategias para enseñar y aprender sus propias lenguas y culturas, sin perder su esencia y su identidad.

PALABRAS CLAVE: Políticas Lingüísticas. Lenguas Indígenas. Ye’kwana. Roraima.

ABSTRACT: The proposed article aims to reflect on the indigenous language policies developed by the indigenous peoples of Roraima, given the multilingual and multicultural reality of the constitution of state, with special attention to the educational actions developed by the Ye'kwana people. In order to understand the tense relations between the Brazilian state and the indigenous languages of Roraima, we are based on the Linguistic Policies literature (CALVET, 2007; COOPER, 1997 [1989]; SILVA, 2018). It was also necessary to recover the research carried out on the Ye'kwana (COSTA, 2013, 2018, 2019; ANDRADE, 2007, 2013), as well as to important the history of linguistic policies for indigenous peoples in Brazil and discuss the indigenous linguistic policies designed and developed by indigenous peoples in Roraima territory (CUNHA, 2008; BRASIL, 1988, 1996; BANIWA, 2006; REPETTO, 2008). We conclude that, due to the State's omission, the Ye'kwana and other indigenous peoples have sought to create policies to try to maintain their traditional values within the needs that contemporaneity and society demand, by documenting and creating strategies to teach and learn their own languages and cultures, without losing their essence and their identity.

KEYWORDS: Language Policies. Indigenous Languages.Ye’kwana. Roraima.

\section{CONSIDERAÇÕES INICIAIS}

As políticas linguísticas ${ }^{1}$ para desenvolvimento de ações educacionais são bastante difusas, dada a amplitude do cenário territorial brasileiro. Isso porque, a realidade multilíngue do espaço territorial brasileiro tem sido um fator que permite discussões teóricoanalíticas, principalmente questionamentos no que concerne ao contato de línguas, às políticas linguísticas adotadas e suas implicações para esfera sociocultural. Diante da necessidade de atender às demandas de comunidades específicas, como as dos indígenas, nos deparamos com a realidade superdiversa linguística e culturalmente complexa de criação do estado de Roraima, com seus diferentes sujeitos nacionais, internacionais, línguas e culturas.

${ }^{1}$ Para Calvet (2007), a política linguística é uma maneira de intervir e gerenciar conflitos originários de diferentes usuários das línguas - ou também uma maneira de mobilizar relações de poder por meio do uso das línguas em determinados contextos históricos e sociais. 
O estado de Roraima é o mais setentrional do norte do Brasil, faz fronteira com os estados do Amazonas e Pará, e com os países Venezuela e República Cooperativa da Guiana. Em seu território geográfica há a presença e concentração de povos indígenas que falam mais de dez línguas diferentes, pertencentes às famílias linguísticas Caribe, Aruwak e Yanomami. Vejamos a Figura 1, para compreendemos melhor esse cenário linguístico-cultural de tríplice fronteira trilíngue, onde há o confronto, contato e o diálogo de distintas nacionalidades, línguas estrangeiras, línguas de imigração e etnias indígenas:

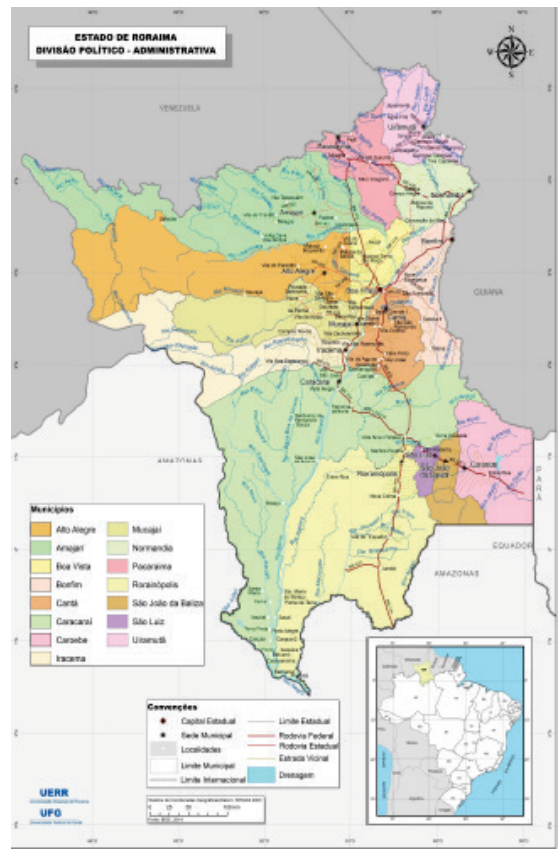

Figura 1: Mapa da Fronteira Tríplice do Estado de Roraima

Fonte: SILVA et al. (2020).

As línguas Caribe faladas em Roraima são sete: Macuxi, Taurepang, Ingarikó, Patamona, Waimiri-Atroari, Ye’kwana e Wai-Wai. De acordo com recente pesquisa desenvolvida pelo Instituto Socioambiental e o Instituto do Patrimônio Histórico e Artístico Nacional (IPHAN, 2019) foi detectada a existência não apenas de quatro, como se tinha notícia, mas seis línguas distintas da família Yanomami, a saber: Yanomami, Sanöma, Ninam, Yanomam, Yaroame, Yãnoma. Já a língua Wapichana é a única representante da família linguística do Aruwak presente em Roraima.

É perceptível, portanto, que todas essas línguas indígenas são responsáveis por um contingente populacional que tem muito impacto sobre as ações de educação pública do estado de Roraima, uma vez que o estado possui a segunda maior população indígena do Brasil, tendo um número significativo de escolas públicas para comunidades indígenas.

Segundo dados do Censo Escolar (GOVERNO DE RORAIMA, 2018), Roraima possui mais de 16 mil alunos indígenas e 260 escolas indígenas. No entanto, muitos desses indígenas precisam deslocar-se para estudar nas escolas da capital, Boa Vista, que não estão preparadas para atender à demanda desse público, com suas necessidades linguísticas e culturais diferenciadas e, consequentemente, que se configuram como específicas.

Nesse cenário linguístico roraimense, encontram-se o povo Ye’kwana, caso particular, dentre os povos indígenas que habitam o estado de Roraima, sobre o qual nos debruçaremos neste artigo, que tem como objetivo apresentar uma análise do que tem sido desenvolvido em termos de políticas linguísticas voltadas para os aspectos educacionais do povo Ye’kwana, bem como comparar com ações educacionais elaboradas e adotadas por outros povos indígenas roraimenses.

Para tanto, na próxima seção, apresentaremos um panorama da legislação sobre políticas linguísticas inclinada para as línguas indígenas que habitam o território brasileiro. Logo após, mostraremos as ações educacionais que o povo Ye’kwana tem 
materializado para manutenção de sua língua e cultura e como essas ações se concretizam enquanto políticas linguísticas. Por fim, traremos algumas considerações sobre outras ações de povos originários de Roraima para vitalizar o uso das suas línguas indígenas em suas comunidades.

\section{POLÍTICAS LINGUÍSTICAS PARA OS POVOS INDÍGENAS NO BRASIL}

Desde o início do século XVI, durante o processo de colonização do Brasil, diversas ações de políticas linguísticas foram implementadas no território pelos portugueses. É relevante ressaltar que as mais marcantes foram aquelas para desenvolvimento de ações educacionais para o ensino de língua portuguesa de forma impositiva para os povos originários que habitam espaço geográfico brasileiro. Durante esse período, a política linguística de educação escolar indígena foi pautada, a princípio, pelo processo de catequização feita pelos missionários jesuítas e, posteriormente, pela integração forçada dos indígenas de diferentes etnias à sociedade nacional por meio da aprendizagem obrigatória da língua nacional. (CUNHA, 2008).

Segundo Cunha (2008), as primeiras ações de políticas linguísticas a favor dos povos e das línguas indígenas começaram a ser oficializadas a partir da publicação da Constituição Federal Brasileira de 1988. Mesmo que de forma tímida, estavam baseadas em discussões oriundas da Declaração Universal dos Direitos Linguísticos, inicialmente, sugeridas em 1987, e somente publicadas em 1996. Vejamos o que diz o $2^{\circ}$ parágrafo do artigo 210 da CF/88 a respeito do ensino de português e o ensino de línguas indígenas:

Art. 210 . Serão fixados conteúdos mínimos para o ensino fundamental, de maneira a assegurar formação básica
comum e respeito aos valores culturais e artísticos, nacionais e regionais.
$\$ 1^{\circ} \mathrm{O}$ ensino religioso, de matrícula facultativa, constituirá disciplina dos horários normais das escolas públicas
de ensino fundamental.
$\$ 2^{\circ} \mathrm{O}$ ensino fundamental regular será ministrado em língua portuguesa, assegurada às comunidades indígenas
também a utilização de suas línguas maternas e processos próprios de aprendizagem. (BRASIL, 1988, não
paginado)

Embora o artigo 210 determine que o ensino fundamental regular seja ministrado em língua portuguesa, é assegurado também às comunidades indígenas a utilização das suas línguas maternas no processo de ensino/aprendizagem, o que se configura como uma primeira tentativa de legislar sobre o direito à língua dos povos minorizados ${ }^{2}$. No entanto, também percebemos, neste artigo, a ideologia predominante que envolve o ensino de língua portuguesa como língua majoritária, com a finalidade de manutenção e propagação do ideal da homogeneidade linguística da unidade nacional.

Concordamos com Silva (2018), quando o autor argumenta que as políticas e planejamentos linguísticos ${ }^{3}$ oficializadas pelo Estado brasileiro ao longo do tempo podem promover o multilinguismo no processo de ensino/aprendizagem de línguas na escola e na sociedade, como também podem instauram um caráter de exclusão dessa mesma realidade diversa que circula na sociedade brasileira.

Em outras palavras, dependendo do grupo social que esteja no poder, exercendo funções legislativas, poderemos ter políticas linguísticas democráticas que considerem essa realidade multilíngue e social da constituição do Estado brasileiro, como é o caso de ações pensadas para as línguas indígenas em dados momentos histórico e sociais, ou podemos ter ações que minimizam e excluem essas realidades, com o intuito de perpetuar a unidade linguística e social do Estado-Nação por meio da imposição da língua oficial.

\footnotetext{
${ }^{2} \mathrm{O}$ conceito de línguas minorizadas está relacionado com aquelas línguas faladas por grupos de pessoas num país que tem por oficial uma língua diferente, isto é, são línguas naturais, não criadas artificialmente, tradicionalmente usadas por parcelas da população de um país, e que não se confundem com dialetos da língua oficial (FERRAZ, 2013).

${ }^{3}$ Cooper (1997 [1989]) identificou uma questão comum ao revisar conceitos relacionados às políticas linguísticas de mais variadas línguas do mundo. Segundo o teórico, existem quatro forças propulsoras mobilizadas no âmbito das políticas e dos planejamentos linguísticos no mundo: "Quem planeja? O quê? Para quem? E como?".
} 
É interessante mencionar, ainda, que a língua sempre foi considerada um elemento central para a definição dos dispositivos de imposição da ideia de nacionalidade. Isso ocorre, porque os grupos - no início uma minoria - que dominavam a língua nacional, considerada como padrão, eram grupos que detinham um poder político e cultural sem precedentes. Em linhas gerais, essa língua das elites dominantes se transformou na língua oficial dos Estados modernos, principalmente a partir da generalização e imposição dos sistemas educacionais de ensino no Brasil.

Em 1996, com a publicação da Lei de Diretrizes e Bases da Educação (LDB), temos uma nova política linguística destinada à educação brasileira, visto que a dada lei apresenta um novo rumo para o ensino de línguas no cenário educacional brasileiro, entre outras questões. A respeito das línguas indígenas, a LDB (1996), em seus artigos 78 e 79 regulamenta que:

Art. 78. O Sistema de Ensino da União, com a colaboração das agências federais de fomento à cultura e assistência aos índios, desenvolverá programas integrados de ensino e pesquisa, para oferta de educação escolar bilíngue e intercultural aos povos indígenas, com os seguintes objetivos:

I - proporcionar aos índios, suas comunidades e povos, a recuperação de suas memórias históricas; a reafirmação de suas identidades étnicas; a valorização de suas línguas e ciências;

II - garantir aos índios, suas comunidades e povos, o acesso às informações, conhecimentos técnicos e científicos da sociedade nacional e demais sociedades indígenas e não-índias.

Art. 79. A União apoiará técnica e financeiramente os sistemas de ensino no provimento da educação intercultural às comunidades indígenas, desenvolvendo programas integrados de ensino e pesquisa.

$\$ 1^{\circ}$ Os programas serão planejados com audiência das comunidades indígenas.

$\$ 2^{\circ}$ Os programas a que se refere este artigo, incluídos nos Planos Nacionais de Educação, terão os seguintes objetivos:

I - fortalecer as práticas sócio-culturais e a língua materna de cada comunidade indígena;

II - manter programas de formação de pessoal especializado, destinado à educação escolar nas comunidades indígenas;

III - desenvolver currículos e programas específicos, neles incluindo os conteúdos culturais correspondentes às respectivas comunidades;

IV - elaborar e publicar sistematicamente material didático específico e diferenciado. (BRASIL, 1996, não paginado)

Dessa forma, é possível identificar as forças propulsoras dessa ação de política para desenvolvimento de ações educacionais das línguas indígenas, como apontado em Cooper (1997[1989]). O estado brasileiro, enquanto força propulsora, se encarrega, juntamente com agências federais de fomento à cultura e de assistência aos indígenas, de pensar de que forma ocorrerá esse trabalho com a tradição linguística e cultural dos povos indígenas.

Assim, é perceptível, mais uma vez, uma ação da ideologia predominante sobre as línguas minorizadas, pois os principais atores dessa política linguística, os povos indígenas, não tem voz e representatividade para participar da criação das políticas linguísticas que irão interferir e gerenciar os usos e funcionamentos de suas línguas/culturais.

De acordo com Calvet (2007, p. 11), “[... sempre houve e haverá indivíduos tentando legislar, ditar o uso correto ou intervir na forma da língua. De igual modo, o poder político sempre privilegiou essa ou aquela língua, escolhendo governar o Estado em uma língua ou mesmo impor à maioria a língua de uma minoria”. Nessa concepção, Cunha (2008) esclarece que antes mesmo dessa regulamentação, já surgia uma ação, por parte dos indígenas, para um processo de ensino/aprendizagem de forma diferenciada em suas comunidades (CUNHA, 2008, p.1).

Em novembro de 1999, as escolas voltadas para os índios - até então, indiferenciadas das chamadas "escolas rurais" - passaram a ser tratadas como instituições de ensino com diretrizes específicas, a partir da Resolução n ${ }^{\circ}$ 3 publicada pela Câmara de Educação Básica do Conselho Nacional de Educação. Em 2000, a Câmara dos Deputados decreta o Plano Nacional de Educação e estipula entre suas metas a criação da categoria oficial de "escola indígena" para assegurar a especificidade do modelo de educação intercultural e bilíngue. 
Portanto, podemos perceber que cada vez mais os povos indígenas brasileiros, a partir das suas próprias demandas e de suas reivindicações, começaram, nas últimas duas décadas, a ser mobilizar para criar suas próprias ações de políticas linguísticas, com a finalidade de valorização das línguas indígenas por meio da elaboração de materiais de ensino, legislações sobre suas próprias línguas como uma forma de realizar o fortalecimento da sua identidade étnica e linguística.

De acordo com Baniwa (2006), as línguas indígenas são importantes elementos culturais de autoestima e de afirmação identitária desses grupos étnicos, ao lado de outros elementos culturais, como a relação com a terra, a ancestralidade cosmológica, as próprias tradições culturais, os rituais e as cerimônias. Nesse sentido, foi sabendo desses aspectos que os colonizadores, desde o início, impuseram a esses povos o autoritarismo do monolinguismo, tornado a língua estrangeira - o português - a única a ser oficialmente reconhecida no território brasileiro.

De fato, é inquestionável que as políticas linguísticas de línguas indígenas adotadas pelo Brasil são mais "conscientes" em comparação com as constituições da década de 1930 em toda a América espanhola (ALFARO, 2001, p. 40). Entretanto, é importante que os povos indígenas lutem pela garantia de seus direitos linguísticos e pelo direito de legislar sobre suas próprias políticas linguísticas.

Na seção seguinte, discutiremos sobre as políticas linguísticas desenvolvidas pelo povo Ye’kwana, bem como apresentaremos outras ações que tem sido desenvolvida de forma autônoma para a manutenção da língua e mitigação da perda linguística das comunidades Ye'kwana.

\section{OS YE'KWANA: QUEM SÃO, QUANTOS SÃO E ONDE ESTÃO}

Os Ye'kwana falam uma língua Caribe do ramo Guianense (GILDEA, 2012). Eles habitam três comunidades localizadas na Terra Indígena Yanomami, Fuduuwaduinha (em vermelho), Waichanha (em azul), e Kudaatanha (em amarelo), de acordo com o mapa a seguir:

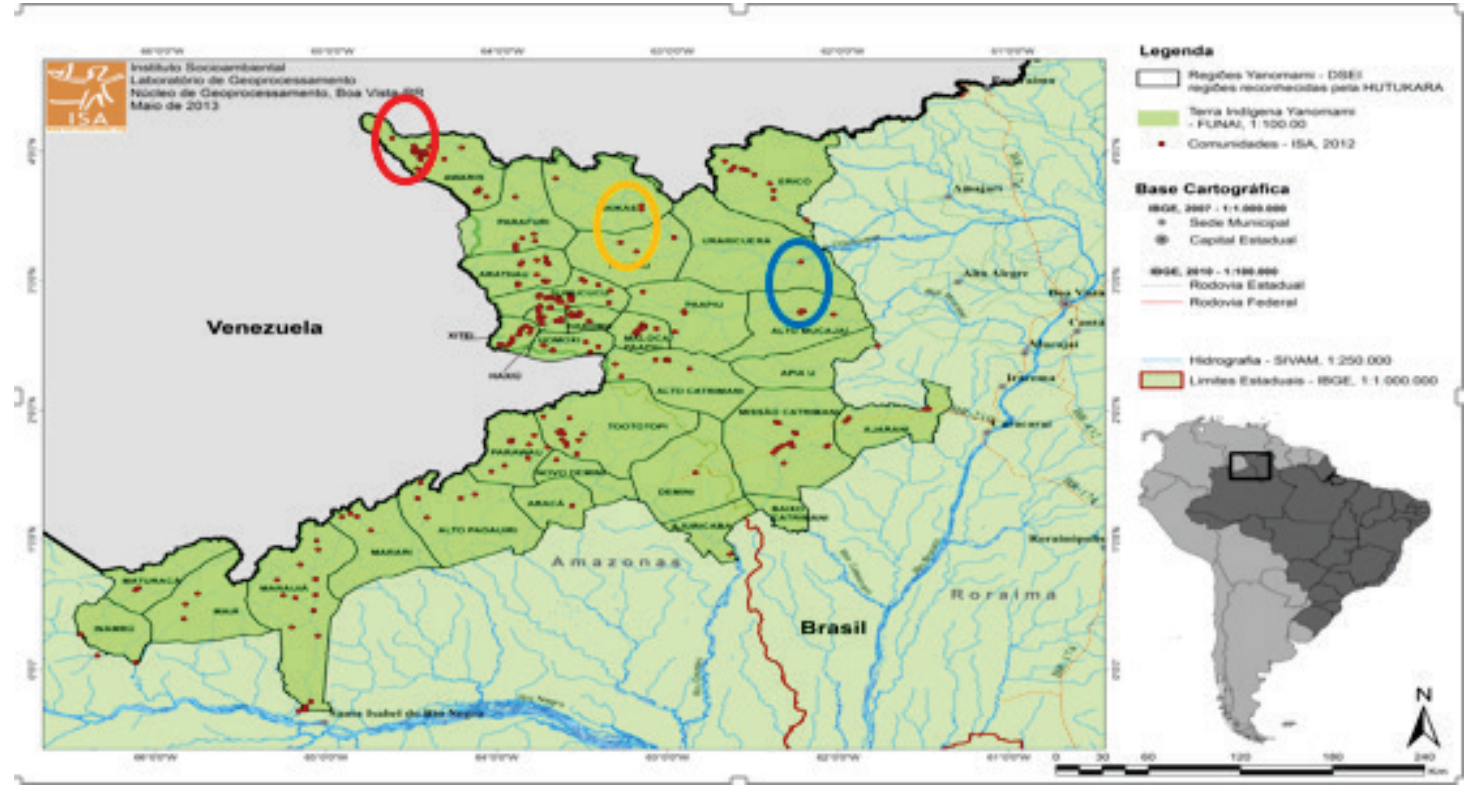

Figura 2 : Terra Indígena Yanomami, com destaque para as aldeias Ye’kwana

Fonte: Instituto Socioambiental (2013) 
De acordo com o diagnóstico sociolinguístico realizado para a Organização das Nações Unidas (UNESCO), ${ }^{4}$ em 2019, os Ye’kwana passaram de uma população de 670, em 2018, para 784 pessoas (COSTA, 2019), em função da migração venezuelana para o Brasil, por causa da crise político, social, econômica e humanitária vivida no país. Eles constituíram uma comunidade inteira de parentes que vieram em busca de alimentação, atendimento de saúde e de educação.

Cada uma das três comunidades tem uma escola que atende alunos até o $9^{\circ}$. ano do Ensino Fundamental, com professores Ye’kwana em processo de formação superior ou graduados. Há um professor que é mestre em Antropologia Social, (PPGAS/Museu Nacional - Universidade Federal do Rio de Janeiro - UFRJ).

Outrossim, há um professor e uma professora que estão em processo de conclusão dos seus mestrados pela Universidade Federal de Minas Gerais - UFMG, respectivamente, em Educação e em Antropologia. E um professor em fase de conclusão do mestrado de Letras da Universidade Federal de Roraima - UFRR.

Além das investigações realizadas pelos próprios Ye’kwana, outros pesquisadores vêm atuando junto ao povo para orientar a elaboração de projetos para captação de recursos e desenvolvimento de pesquisas, como por exemplo, podemos citar o trabalho de Lauriola (2003), que, além da pesquisa acadêmica, desde 2003 auxilia os Ye’kwana na implantação do sistema de radiofonia. Além dela, temos Andrade $(2007,2013)$ que auxiliou na criação da Wanaaseduume Associação Ye’kwana, organização que atua defendendo os interesses do povo Ye’kwana no Brasil.

Desde 2010, Costa $(2013,2018)$ vem desenvolvidos pesquisas e trabalhos de documentação e análise linguística da língua Ye’kwana faladas no território brasileiro. Juntas, Andrade e Costa, trabalharam na elaboração de materiais didáticos com o povo Ye’kwana na ação Saberes Indígenas na Escola. Atualmente, estão trabalhando no Dicionário Enciclopédico Multimídia da Língua Ye’kwana, no âmbito do Projeto de Documentação de Línguas Indígenas (PRODOCLIN), do Museu do Índio/FUNAI em parceria com a UNESCO.

Além dessas pesquisadoras, temos também outras investigações desenvolvidas por pesquisadores que têm trabalhado em parceria com os Ye’kwana, para a elaboração de projetos, programas, produtos e políticas de atuação na sociedade não indígena.

Esse cenário, com profissionais indígenas e não indígenas qualificados, desenha o amadurecimento da percepção dos Ye’kwana sobre as necessidades específicas do seu povo, especialmente no que tange à educação. Assim, a adesão a programas e projetos que tenham a perspectiva de auxiliar na construção dessa ideia, vem se desenvolvendo desde 2012, como iremos relatar na seção a seguir.

\section{AS POLÍTICAS LINGUÍSTICAS AUTÓCTONES DOS YE’KWANA}

Desde 2011, não apenas os professores como todas as comunidades Ye'kwana vinham manifestando uma absoluta inquietação sobre a adequação das necessidades burocráticas para manutenção da rotina escolar (exigida pela Secretaria de Educação de Roraima), às necessidades específicas do povo Ye'kwana.

No ano de 2012, os Ye’kwana realizaramtrês oficinas: a 1 ${ }^{a}$ Oficina do Dicionário Ye’kwana; a Oficina de Miçangas e de elaboração do Projeto Político Pedagógico das escolas Ye’kwana (COSTA, 2013). Essa última foi organizada pelo Instituto Socioambiental (ISA), em parceria com a Associação Ye’kwana.

Cabe mencionar que a própria realização da Oficina do Dicionário refletia, naquele momento, uma demanda dos Ye’kwana por materiais para ensino-aprendizagem da língua, tendo em vista que muitos povos indígenas trazem esse entendimento, por vezes

${ }^{4}$ Este Diagnóstico faz parte do Produto 02 do Subprojeto Ye’kwana, referente ao Projeto Dicionários Multilíngues de Línguas Indígenas promovido pela UNESCO em parceria com o Museu do Índio /Fundação Nacional do índio- FUNAI. 
equivocado, de que a aprendizagem de uma língua perpassa pela existência de um dicionário daquela língua. Assim, visando atender a esse pedido, foi realizada a oficina com a participação de professores, alunos e da comunidade em geral.

Nesse mesmo período, foi realizada a Oficina de Miçangas, com objetivo de documentar a elaboração de enfeites de miçanga, documentar as narrativas e a iconografia envolvida na elaboração das peças. Essa atividade foi uma realização da UNESCO, por meio do Projeto de Documentação de Culturas Indígenas (PRODOCULT), coordenado pelo Museu do Índio do Rio de Janeiro (FUNAI/RJ). Os materiais coletados para esse projeto foram vendidos para compor o acervo do Museu, e hoje ${ }^{5}$ parte dele encontrase em exibição na exposição "No caminho da Miçanga".

O material filmado também deu origem a um pequeno filme que conta a história Ye'kwana do surgimento e propagação da miçanga pelo mundo apresenta imagens documentando o processo de elaboração das peças expostas e da apresentação destas para toda a comunidade ao final da oficina.

Assim, as atividades dessa natureza apresentam profundo impacto na construção de conhecimento para fortalecer as atividades cotidianas de um povo. A prova disso é que, a partir dela, surgiram outros trabalhos de documentação realizados pelos próprios Ye'kwana (cf. CAJUSUANAIMA ROCHA, 2014; RODRIGUES, 2014) ao reconhecer/perceber a necessidade de salvaguardar informações sobre seu patrimônio artístico-cultural.

Paralelamente a essas atividades, a Oficina do Projeto Político Pedagógico (doravante PPP) configurava-se como uma necessidade burocrática que precisava adequar-se às especificidades dos Ye’kwana, pois eles buscavam a valorização da sua cultura por meio dos mecanismos de regulamentação das atividades escolares dentro do paradigma sociocultural Ye’kwana.

Desse modo, o PPP das escolas em várias oficinas, com a participação de toda a comunidade (homens maduros, mulheres, alunos e professores) e com a participação do Instituto Socioambiental. A percepção da necessidade de ter um projeto orientado para as práticas da comunidade se configura como uma política linguística das mais eficazes, pois, nas palavras dos próprios Ye’kwana: “[...] vimos que sem uma escola diferenciada e um Projeto Político Pedagógico (PPP) elaborado por nós mesmos, a nossa cultura corre maior risco de, aos poucos, cair no esquecimento das gerações mais jovens, bem como da sociedade em geral (PPP YEKWANA, 2015, p. 6).

Além disso, uma das decisões para esse PPP foi a de manter um calendário diferenciado para cada escola, de acordo com os interesses e as atividades comunitárias, como as cerimônias tradicionais de construção de casa e limpeza de roça nova ${ }^{6}$, inclusive, com aulas aos sábados, domingos e feriados, seguindo ritmo da comunidade.

As atividades comunitárias são realizadas seguindo a ciclo da natureza (tempo das chuvas, tempo de colheita, aparecimento das estrelas, entre outros) e deste dependem atividades como a caça, a pesca, a coleta de recursos da floresta, o roçado e construções de casa. Cabe esclarecer que esse calendário diferenciado é significados, visto que obedecer aos feriados nacionais e religiosos e aos finais de semana, que não são parte do conhecimento Ye'kwana, impacta, muitas vezes, no aprendizado de importantes saberes tradicionais.

Outrossim, para cada escola foi decidido pela realização de reuniões com a comunidade para construir um calendário próprio que respeite as especificidades da cultura Ye'kwana seguindo a legislação destacada na Resolução n. 3, do Conselho Nacional de Educação (CNE, 1999) de 10 de novembro de 1999, que diz:

\footnotetext{
${ }^{5}$ Durante a elaboração deste artigo, em março de 2020, a exposição, que tem curadoria de Els Lagrou, encontrava-se no Museu do Índio (cidade do Rio de Janeiro), com exibição restrita em função de adaptações do prédio.

${ }^{6}$ Sobre este tema, Cajusuanaima Rocha (2021) explica que, para a abertura de uma roça nova, é necessário um conjunto de práticas coletivas que contemplam rituais de limpeza e purificação do novo lugar.
} 
Art. $4^{\circ}$ - As escolas indígenas, respeitados os preceitos constitucionais e legais que fundamentam a sua instituição e normas específicas de funcionamento, editadas pela União e pelos estados, desenvolverão suas atividades de acordo com o proposto nos respectivos projetos pedagógicos e regimentos escolares com as seguintes prerrogativas:

I - organização das atividades escolares, independentemente do ano civil, respeitando o fluxo das atividades econômicas, sociais, culturais e religiosas;

II - duração diversificada dos períodos escolares, ajustando-as às condições e às especificidades próprias de cada comunidade.

Diante do exposto, apresentamos algumas ações pontuais do povo Ye’kwana visando a manutenção de sua língua e cultura. Essas ações se configuram desde a adesão a programas de documentação (junto a outras entidades, governamentais ou não), a produção própria de materiais didáticos e a crescente busca de professores por cursos de graduação e pós-graduação (junto à comunidade escolar).

Por fim, destacamos a elaboração de políticas escolares para a valorização linguística e cultural dos conhecimentos tradicionais (junto a toda a comunidade). Todas essas iniciativas mostram a necessidade que o povo Ye’kwana tem de fortalecer sua língua por meio da tomada de decisões políticas que irão impactar diretamente no ensino e na transmissão da língua para outras pessoas.

\section{OUTROS CASOS DE POVOS INDÍGENAS COM POLÍTICAS LINGUÍSTICAS PRÓPRIAS EM RORAIMA}

Como vimos anteriormente, as políticas linguísticas destinadas aos povos indígenas começaram a ser desenvolvidas a partir da publicação da CF/88 e na LDB/96. No entanto, os povos indígenas e suas lideranças já se articulavam, com a finalidade de criação de políticas públicas específicas destinadas às demandas dos povos indígenas, bem como também das suas questões educacionais, tais como: o reconhecimento étnico, o reconhecimento de uma cidadania diferenciada e a superação do fracasso do modelo escolar indígena, que durante muito tempo foi oficializado em documentos governamentais por meio de um discurso assimilacionista e paternalista, o qual não foi capaz de garantir o mínimo de condições as comunidades indígenas (BANIWA, 2006).

Em outras palavras, corroboramos o pensamento de Repetto (2008), quando o teórico argumenta que as políticas linguísticas adotadas pelo estado brasileiro serviram como uma forma de controle para a busca de uma integração nacional. Vejamos:

Chamamos a atenção para o fato de que, embora a educação escolar nas comunidades indígenas foi imposta como mais um instrumento de controle do sistema nacional sobre os povos indígenas, no contexto mais amplo da "integração nacional", ela foi se transformando ao longo do tempo em necessidade e reivindicação, por meio da qual, se busca, a partir da perspectiva indígena, moldar ferramentas de sobrevivência e de luta. (REPETTO, 2008, p. 28)

Nesse sentido, podemos dizer que nas últimas décadas, os povos indígenas não satisfeitos com os modelos de educação impostos pelo estado brasileiro, começaram a buscar uma definição própria para si, pensando em suas demandas específicas e, consequentemente, buscando a criação de políticas linguísticas autóctones que levantassem a bandeira de uma educação mais específica e diferenciada.

Esse é o caso do povo Wapichana, um dos povos pertencentes à Terra Indígena Serra da Lua, no município de Cantá, em Roraima, que semestralmente realiza um encontro de professores de língua indígena para sondar as dificuldades e avanços no ensino da língua, sem contar com apoios institucionais.

Essa foi uma iniciativa dos próprios professores que, com base nas suas vivências resolveram criar um espaço para dividir propostas e discutir práticas de ensino de sua língua nas comunidades indígenas. Segundo Repetto (2008, p. 2009): 
Trata-se de uma luta para conquistar espaços jurídicos, políticos, pedagógicos e de gerenciamento desse processo educacional. Desse modo, é que as diferentes vozes e propostas de educação indígena procuram, desde perspectivas diversas, avançar nas definições concretas e particulares, visando consolidar as propostas reais de uma educação significativa para esses povos.

Além do caso dos professores Wapichana mencionados acima, é importante lembrar da iniciativa dos professores Macuxi que, em 2018, elaboraram um protocolo, com o objetivo de desenvolver junto com seus alunos, em sala de aula, pequenas gramáticas colaborativas para ensino da sua língua a partir dos dados disponibilizados por qualquer falante de Macuxi como língua materna.

Esse protocolo auxiliou professores de comunidades distantes dos centros urbanos e que não dispõem de nenhum recurso tecnológico, poucos recursos pedagógicos ou materiais didáticos para auxiliar aos alunos a desenvolverem interesse em aprender sua própria língua.

Portanto, essa falta de interesse não é natural, mas vem sendo cultivada ao longo dos anos, desde a colonização das terras de Roraima pelos imigrantes no início do século XX. Assim, concordamos com as postulações feitas por Repetto (2008, p.29), quando o autor explicita que:

Talvez, por se tratar de um Estado que ostenta uma das maiores populações indígenas do Brasil, há em Roraima um forte preconceito e uma tradição de práticas de violência contra esses povos. Muitas são as forças sociais contrárias aos seus interesses e isto se reflete de forma clara na implantação histórica das políticas educacionais, como na ampliação da rede escolar.

De fato, esse forte preconceito aos povos indígenas ainda é muito evidente no estado de Roraima, principalmente, quando envolve políticas para ações de desenvolvimento da educação escolar indígena. Nos últimos tempos, várias organizações indígenas roraimenses têm se mobilizado para elaborar políticas públicas para o acesso de professores indígenas a cursos específicos que os preparem para o ensino de suas línguas nas comunidades.

É perceptível, porém, que embora haja essa articulação, existem discursos indígenas divergentes, que manifestam diferentes interesses e apresentam prioridades diversas, e, às vezes, conflitantes nos debates políticos e territoriais (REPETTO, 2008).

A partir da emergência desse discurso de articulação entre os povos indígenas e suas lideranças, pensando em demandas específicas, houve a criação de propostas educacionais próprias desses povos, ficando denominadas como escolas-pilotos indígenas, pois são experiências inovadoras que não foram propostas com apoio governamental, ou seja, essa estruturação escolar indígena foi pensada por e para indígenas, um claro exemplo de política linguística autóctone das comunidades indígenas de Roraima.

Baniwa (2006) nos esclarece que essas são as primeiras escolas indígenas ${ }^{7}$ levam em consideração a ideia de educação escolar indígena diferenciada, visto que refletem em seus projetos político-pedagógicos suas vivências, culturas, línguas e especificidades, tendo em vista suas múltiplas realidades sociohistóricas. Em outras palavras são:

Escolas com projetos político-pedagógicos próprios, capazes de atender às necessidades das comunidades específicas e com autonomia na gestão administrativa, política e pedagógica. As escolas indígenas diferenciadas pautam suas estratégias de transmissão, produção e reprodução de conhecimentos na proposta de possibilitar às comunidades indígenas a recuperação de suas memórias históricas, reafirmação de suas identidades étnicas, a valorização de suas línguas, tradições e ciências, a defesa dos seus territórios direitos básicos. (BANIWA, 2006, p.159)

\footnotetext{
${ }^{7}$ Em Roraima, o projeto político-pedagógico das escolas do povo Ye’kwana, produzido em 2015, ainda aguarda aprovação da Secretaria de Educação do Estado de Roraima - SEED/RR
} 
Repetto (2008), em seu artigo, intitulado A Educação Escolar Indígena em Roraima: o processo histórico e as demandas atuais por ensino médio, elaborou uma tabela muito interessante com o número de alunos indígenas no estado de Roraima. Vejamos:

Tabela 1: Progressão do número de alunos matriculados na educação escolar indígena em Roraima ${ }^{8}$

\begin{tabular}{|c|c|c|c|c|c|c|c|c|}
\hline Ano & Pré & $\begin{array}{l}1^{\mathrm{a} a} 4^{\mathrm{a}} \\
\text { série }\end{array}$ & $\begin{array}{l}5^{\mathrm{a}} \mathrm{a} 8^{\mathrm{a}} \\
\text { série }\end{array}$ & $\begin{array}{l}1^{\circ} \mathbf{a} 3^{\circ} \\
\text { Médio }\end{array}$ & EJA EM & EJA Fundamental & Total & $\begin{array}{l}\text { Total Professores } \\
\text { atuando na Ed. Ind. }\end{array}$ \\
\hline 1998 & & 4950 & 1311 & -- & -- & -- & 6.261 & 471 \\
\hline 1999 & & 4867 & 1383 & 154 & -- & -- & 6.404 & 426 \\
\hline 2000 & & 4902 & 1816 & 628 & -- & -- & 7.346 & 565 \\
\hline 2001 & & 4386 & 2004 & 222 & -- & -- & 6.612 & 503 \\
\hline 2002 & & 4827 & 2276 & 412 & -- & -- & 7.515 & 754 \\
\hline 2003 & & 4871 & 2755 & 1237 & -- & -- & 10.916 & \\
\hline 2004 & 1579 & 5905 & 2658 & 1053 & 61 & 1904 & 13.160 & 1000 (aprox) \\
\hline 2005 & 1313 & 5129 & 2835 & 1276 & 160 & 1193 & 11.906 & 1000 (aprox) \\
\hline
\end{tabular}

Fonte: Repetto (2008, p.29)

É perceptível, a partir da tabela elaborada por Repetto (2008), que esse quantitativo de alunos indígenas estudando nos mais variados níveis de ensino é fruto de políticas linguísticas autóctones desenvolvidas no Núcleo de Educação Indígena, que se refletiu na publicação de um documento em $1993^{9}$.

Cabe mencionar que esse documento marca o início da efetiva criação e implementação de políticas linguísticas autóctones do estado de Roraima e que vem sendo reformuladas constantemente, a fim de garantir os direitos linguísticos, educacionais e culturais dos povos indígenas, porém, sabemos não é uma tarefa fácil e que depende de apoio governamental nas ações, bem como uma maior sensibilidade para entender esse processo educacional diferenciado.

Desse modo, essas ações de políticas autóctones têm trazido protagonismo aos povos indígenas, tendo em vista que seus processos de ensino/aprendizagem possuem muitas especificações, como vimos anteriormente. No entanto, é preciso também que haja responsabilidade do estado brasileiro para dar assistência e financiamento no oferecimento de condições técnicas, financeiras e operacionais para implementação e manutenção dessas políticas linguísticas que já existem ou que venham a surgir.

Baniwa (2006) aponta que embora a essas políticas linguísticas autóctones enfrentem grandes dificuldades e barreiras é preciso resistir e persistir no uso dessas políticas, visto que muitas escolas-pilotos já estão sendo incorporadas aos sistemas educacionais oficiais. No entanto, o autor esclarece que não é uma tarefa fácil, tendo em vista que não há nenhuma forma de viabilização administrativa, técnico e financeira para garantir os direitos linguísticos e culturais dessas populações.

\footnotetext{
${ }^{8}$ Para montar esta tabela, Repetto (2008) utilizou os dados oficiais do Censo Escolar 2004 e 2005 do Estado de Roraima. No entanto, ele também informa que os dados disponíveis não estão completos, o que explica a redução do número de alunos em relação ao ano anterior.
} 


\section{CONSIDERAÇÕES FINAIS}

O artigo proposto teve como objetivo refletir sobre as políticas linguísticas autóctones desenvolvidas e implementadas no estado de Roraima por e para povos indígenas, dada a realidade multilíngue e multicultural da criação estado roraimense, com especial atenção para as ações educacionais desenvolvidas pelos povos Ye’kwana, para legislar sobre sua própria língua e cultura.

Além disso, também apresentamos para os leitores outras iniciativas sobre autóctones desenvolvidas por/para povos indígenas em do território roraimense, como: a criação das escola-pilotos dentro das comunidades indígenas, desenvolvimento de materiais didáticos colaborativos e formação continuada dos professores.

Ao longo do texto, percebemos que durante muito tempo as políticas linguísticas eram pensadas e idealizadas a partir da visão do Estado brasileiro. Isso porque, durante o processo de colonização os portugueses idealizaram políticas linguísticas para os povos indígenas para as suas extinções, bem como suas propostas e demandas educacionais.

A política linguística do Estado brasileiro adotada para os povos indígenas era pautada pela catequização feita pelos missionários jesuítas, dentre outros, com o objetivo de que os povos indígenas aprendessem a língua portuguesa e, consequentemente, adotassem a religião católica.

Diante dessa política linguística do Estado brasileiro, nos deparamos com questionamentos e reinvindicações dos povos indígenas que começaram a se articular na tentativa de criar suas próprias políticas linguísticas, que visavam atender às demandas e necessidades das comunidades.

Como exemplo dessas políticas autóctones, criadas a partir da inquietação a respeito das políticas linguísticas adotadas pelo Estado brasileiro, principalmente, aquelas que envolvem ações educacionais, expomos a realização da $1^{\text {a }}$ Oficina do Dicionário Ye’kwana, da Oficina de Miçangas, bem como também a feitura da oficina de elaboração do Projeto Político Pedagógico das escolas Ye’kwana. (COSTA, 2013).

A partir dessas políticas autóctones, o povo Ye’kwana começou a perceber profundo impacto na construção de conhecimento para fortalecer as atividades cotidianas do seu povo, visto que várias pessoas começaram a refletir sobre sua própria língua e cultura, inclusive, fazendo seus trabalhos de documentação e de cunho etnográfico, reconhecendo e percebendo a necessidade de salvaguardar informações sobre seu patrimônio artístico, cultural e linguístico.

Outras políticas autóctones também começaram a ser desenvolvidas no estado de Roraima, a exemplo, a iniciativa dos professores Macuxi que elaboraram um protocolo, com a finalidade de desenvolver junto com seus alunos, em sala de aula, gramáticas colaborativas para ensino da sua língua a partir dos dados disponibilizados por qualquer falante de Macuxi como língua materna, fazendo com que haja a preservação da sua língua e cultura, bem como a perpetuação dessas práticas de linguagem para as próximas gerações.

Portanto, é perceptível que diante das poucas políticas linguísticas implementadas pelo Estado brasileiro ao longo do tempo, os povos indígenas começaram a se organizar e pensar em suas próprias políticas, tendo em vista que desde o processo de colonização suas demandas e especificidades não eram levadas em consideração. Por isso, começaram a se articular com objetivo de legislar sobre suas próprias línguas e culturas, o que tem culminado na criação de políticas linguísticas autóctones de ações educacionais. Essas políticas são pensadas por e para as comunidades indígenas, como os exemplos que vimos nesse artigo sobre os povos Ye’kwana, Wapichana e Macuxi, de Roraima.

Assim, é importante que esses povos indígenas e outros continuem resistindo e lutando para legislar e desenvolver ações para a (re)vitalização de suas próprias línguas, com vistas não apenas ao desenvolvimento educacional de suas comunidades, que é um direito linguístico exposto na Declaração Universal dos Direitos Linguísticos, mas também para o fortalecimento da sua identidade cultural. 


\section{REFERÊNCIAS}

ANDRADE, K. V. A Ética Ye’kuana e o espírito do empreendimento. 2007. Tese (Doutorado) - Programa de Pós-Graduação em Antropologia, Universidade de Brasília, Brasília, 2007.

ANDRADE, K.V. Alteridades (in)corporadas: notas sobre a chefia Ye’kuana. Anuário Antropológico, Brasília, v.38, n.1, p.59-82, 2013. Disponível em: https://periodicos.unb.br/index.php/anuarioantropologico/article/view/6873/6947 Acesso em: 26 jan. 2021.

BANIWA, G. dos S. L. O índio brasileiro: o que você precisa saber sobre os povos indígenas no Brasil hoje. Brasília: MEC/UNESCO, 2006.

BRASIL. Constituição da República Federativa do Brasil. Brasília, DF: Senado, 1988. Disponível em: www.planalto.gov.br/ccivil 03/constituicao/constituicao.htm Acesso em: 26 mar. 2020.

BRASIL. Lei de Diretrizes e Bases da Educação Nacional. Lei nº 9.394, de 20 de dezembro 1996. Disponível em: http://www.planalto.gov.br/ccivil 03/LEIS/19394.htm

Acesso em: 26 mar. 2020.

CALVET, J.-L. As políticas linguísticas. São Paulo: Parábola, 2007.

CAJUSUANAIMA ROCHA, V.. A soberania alimentar do povo Ye’kwana. 2021. Dissertação (Mestrado) - Programa de PósGraduação em Antropologia, Universidade Federal de Minas Gerais, Belo Horizonte, 2021.

CONSELHO NACIONAL DE EDUCAÇÃO. Resolução CEB No 3, DE 10 de novembro de 1999. Disponível em: http://portal.mec.gov.br/cne/arquivos/pdf/rceb03 99.pdf. Acesso em 20 març. de 2020.

COSTA, I. O Número em Ye’kuana: uma perspectiva tipológica. 2013. Dissertação (Mestrado) - Programa de Pós-Graduação em Linguística, Universidade Federal do Rio de Janeiro, Rio de Janeiro, 2013.

COSTA, I. A quantificação em Ye’kwana: a distinção contável-massivo. 2018. Tese (Doutorado) - Programa de Pós-Graduação em Linguística, Universidade Federal do Rio de Janeiro, Rio de Janeiro, 2018.

COSTA, I. Produto 02: Diagnóstico sociolinguístico do povo Ye’kwana. Subprojeto Ye’kwana. Cidade do Rio de Janeiro: PRODOCLIN, UNESCO / Museu do Índio, 2019.

COOPER, R. L. La planificación linguística y el cambio social. Cambridge: University Press, 1997[1989].

CUNHA, R. B. Políticas de línguas e educação escolar indígena no Brasil. Educar, Curitiba, n.32, p. 143-159, 2008. Disponível em: http://www.scielo.br/scielo.php?pid=S0104-40602008000200011\&script=sci arttext. Acesso em: 25 mar. 2020.

FERRAZ, A. P. O panorama linguístico brasileiro: a coexistência de línguas minoritárias com o Português. Filol. lingüíst., n. 9 , p. 43 73, 2007.

GOVERNO DE RORAIMA. Resultado do Censo Escolar 2018. 2018 Disponível em: http://dadosroraima.com/2019/04/resultadodo-censo-escolar-2018/. Acesso em: 20 mar. 2020. 
INSTITUTO DO PATRIMÔNIO HISTÓRICO E ARTÍSTICO NACIONAL. 2019. Proteção as línguas e tradições indígenas. Disponível em: http://portal.iphan.gov.br/noticias/detalhes/3497/protecao-as-linguas-e-tradicoes-indigenas. Acesso em 20 març de 2020 .

INSTITUTO SOCIOAMBIENTAL. Terra Indigena Yanomami. 2013. Disponível em: https://www.socioambiental.org/ptbr/tags/terra-indigena-yanomami . Acesso em: 20 mar. 2020.

LAURIOLA, E. M. Amazônia em movimento: "redes” e percursos entre os índios Ye’kuana, Roraima. Cadernos de Campo, Cidade, v. 11, n. 11, p.21-35, 2003.

REPETTO, M. A educação escolar indígena em Roraima: O processo histórico e as demandas atuais por ensino médio. In: OLIVEIRA, R. da S. (org.). Roraima em foco: pesquisa e apontamentos recentes. Boa Vista: Editora da UFRR, 2008. p. 50-68.

RODRIGUES, J. Ye’kuana nödöjätöödö: artesanato Yekwana. 2014. Trabalho de Conclusão de Curso (Graduação) - Curso de Gestão Territorial Indígena - Patrimônio Indígena, Universidade Federal de Roraima, Boa Vista, 2014.

SILVA, G. de F, N. et al. Atlas Escolar de Roraima. Boa Vista - RR: UERR Edições, 2020.

SILVA, M. V. da. (Des) Políticas Linguísticas no Brasil: A Reforma do Ensino Médio e a Exclusão do Ensino de Língua Espanhola na Educação Básica. Revista Diálogos, [S.1.], v. 6, n. 2, p. 233 - 245, maio 2018. Disponível em: http://periodicoscientificos.ufmt.br/ojs/index.php/revdia/article/view/5894. Acesso em: 26 mar. 2020.

YEKUANA. 2015. 1 vídeo. Publicado pelo Canal do Museu do índio do Rio de Janeiro. Disponível em: https://www.youtube.com/watch?v=AUeVU4RLnmU. Acesso em: 26 set. 2021.

\section{()(1) $\circledast$}

Recebido em 26/03/2021. Aceito em 26/06/2021. 